\title{
FENOMENOLOGIA DA EDUCAÇÃO NUMA ERA DE TÉCNICA E TECNOLOGIAS DA INFORMAÇÃO
}

\author{
Ezir George Silva* \\ Ferdinand Röhr**
}

\begin{abstract}
RESUMO: A pesquisa em torno do pensamento filosófico de Gabriel Marcel inscreve-se nos discursos sobre Filosofia, Educação e Tecnologias da Informação. Consiste em examinar a interação entre os fenômenos estáveis e instáveis da relação dialética entre as tecnologias da informação e as estruturas da vida interpessoal do sujeito educando, a partir dos pressupostos da Filosofia da Existência e da Filosofia da Esperança.
\end{abstract}

Palavras-chave: fenomenologia; educação; tecnologias da informação; Marcel.

RESUMEN: La presente investigación sobre el pensamiento filosófico de Gabriel Marcel se inscribe en los discursos sobre Filosofía, Educación y Tecnologías de la Información. La misma consiste en examinar la interacción entre los fenómenos estables e inestables de la relación dialéctica entre las tecnologías de la información y las estructuras de la vida interpersonal del sujeto educando, a partir de los presupuestos de la Filosofía de la Existencia y de la Filosofía de la Esperanza.

Palabras clave: fenomenología; educación; tecnologías de la información; Marcel.

\section{Introdução}

Gabriel Marcel nasceu em 7 de dezembro de 1889 e faleceu em 8 de outubro de 1973, na cidade de Paris, na França. Como filho de Henry Marcel e Laura Meyer, Marcel provém de uma família de tradição alemã e ascendência judia, por parte de sua mãe. Seu pai, “[...] é um dos homens mais cultos de sua geração, como se diz, um herdeiro da melhor tradição [...]" (PARAJÓN apud MARCEL, 2002, p. XI).

\footnotetext{
* Doutor e Mestre em Educação pela Universidade Federal de Pernambuco - UFPE. Professor Adjunto da Universidade Federal Rural de Pernambuco UFRPE. Departamento de Educação. ezo.silva@hotmail.com

${ }^{*}$ É Dr. Phil. Pela Rheinisch-Westfälisch Technische Hochschule Aachen, Alemanha; é Professor Titular do Departamento de Fundamentos Sócio-Filosóficos da Universidade Federal de Pernambuco - UFPE, membro do Programa de Pós-Graduação em Educação e Espiritualidade da mesma universidade. ferdinanrohr@gmail.com
}

Na infância, Gabriel Marcel conviveu com as ausências de seu pai, a experiência de ser filho único e a perda de sua mãe, em 15 de novembro de 1893, quando lhe faltavam três semanas para completar quatro anos. Criado numa atmosfera de ternura, tensão e solicitude, desde muito cedo, conversa, por falta de companhia, com irmãos, personagens e amigos imaginários ${ }^{2}$. Vemos,

\footnotetext{
${ }^{2}$ Marcel descreve a força e o caráter das influências que seu universo infantil exerceu sobre seu pensamento filosófico e sua produção de dramatúrgico, dizendo: "Senti desde muito cedo uma espécie de embriaguez, não somente ao evocar seres diferentes de mim, mas ao identificar-me completamente com eles, servindo-lhes de intérprete [...] Sempre achei que os personagens de teatro, que eu gostava de fazer dialogar, me fizeram às vezes, no princípio, de irmãos e irmãs de que se sentia tanta falta. Outra circunstância contribuiu sem dúvida para o desenvolvimento de meu talento dramático. Sentia-me inclinado, desde a infância, a observar, entre os que compunham o meio familiar em que vivia, divergências de pontos de vista e de temperamento
} 
então, um conjunto de vivências por onde já se esboça sua vocação dramatúrgica; e o processo de cultivo da imaginação, que o leva, aos oito anos de idade, a escrever suas primeiras obras teatrais: Júlio e, depois, Camuse, em 1897. Isto explica, em parte, porque Marcel fez das categorias da existência-concreta e da relação intersubjetiva o mote central, tanto da sua crítica literária, como da sua produção teatral ${ }^{3}$, musical $^{4}$ e pesquisas filosóficas 5 e pedagógicas.

que me obrigaram a tomar prematuramente consciência dos insolubilia que, muitas vezes, as relações humanas aparentemente mais simples comportam" (TROISFONTAINES, 1966, p. 236).

3 Um conjunto de informações biográficas e pormenorizadas da produção teatral de Gabriel Marcel achar-se-á na obra "Un Filósofo Itinerante: Gabriel Marcel (1963)". Este texto é fruto da convivência pessoal de M. M. Davy com nosso autor. Um estudo que está dividido em três partes: na primeira, Davy nos convida a caminhar com Marcel por sua trajetória familiar e processos formativos. Na segunda, nos descreve a natureza do pensamento dramatúrgico marceliano. E, na terceira, propõe-se a analisar algumas de suas obras teatrais, concluindo com uma nota destinada a seus leitores e espectadores. Ao tomar como base o teatro marceliano, Davy nos coloca diante das grandes intuições do nosso dramaturgo, nos convida a caminhar rumo a uma luz pressentida, mais que simplesmente vista, que apesar das trevas, chama-nos ao consolo e à esperança nos dias de hoje.

4 A estética musical de Gabriel Marcel está estreitamente ligada às experiências contínuas e descontínuas de sua existência, ao seu teatro e à pesquisa filosófica. Sobre a relação entre dramaturgia ${ }^{4}$, existência e filosofia, é dito, pelo próprio autor, que esta forma de expressão do pensamento, não só trazia consolo à sua solidão, como contribuía para a ampliação e construção do olhar itinerante de sua filosofia. Servia, sobretudo, para alargar seus horizontes conceituais a respeito da condição humana e de suas interfaces multidimensionais (MARCEL, 1980).

${ }^{5}$ A produção Literária e Filosófica de Marcel começou a ser publicada no mesmo ano em que Martin Heidegger publica Sein und Zeit (O Ser e o Tempo).
Depois de seu bacharelado e sua licenciatura em Filosofia, Gabriel Marcel obteve o diploma no Curso de Estudos Superiores, na Université Paris-Sorbonne - França ${ }^{6}$, com um estudo, nas próprias fontes, sobre 'Les Idées Métaphysiques de Coleridge Dans Leurs Rapports Avec La Philosophie de Schelling'. "A escolha deste tema indica, desde o início, o sentido de suas preocupações e seu gosto pelos autores metafísicos ingleses e alemães" (DAVY, 1963, p. 23). Esta tese foi apresentada em 1909 e publicada em 1971. Movido pela inquirição, passou a assistir, nesta mesma época, as aulas dos professores Charles Péguy, Jacques Maritain y Henri Bergson?.

"O Journal Métaphysique, por exemplo, divide-se em duas partes; a primeira, que vai de primeiro de janeiro de 1914 a oito de maio do mesmo ano; e a segunda parte, de quinze de setembro de 1915 a vinte quatro de maio de 1923" (CARMONA, 1995, p. 62). "É redigindo este Journal à maneira de Kierkegaard (Diário de um Sedutor) ou de Maine de Biran (Journal Intime) que ele vai tomar consciência de sua 'existência' no sentido mais ontológico do termo [...]" (HUISMAN, 2001, p. 83). É a produção desta obra que fará de Marcel uma das principais vozes da Filosofia da Existência e que o porá, imediatamente, na primeira fileira dos filósofos existencialistas.

${ }^{6}$ As traduções das referências do francês, do alemão, do inglês e do espanhol para o português é de responsabilidade nossa.

7 Em palestra sobre "Kierkegaard Vivant", proferida no Colóquio organizado pela UNESCO, em Paris, de 21 a 23 de abril de 1964, Gabriel Marcel comenta a respeito da "[...] mais profunda admiração que tem por Bergson, cujos cursos no Collège de France, teve o privilégio de seguir durante dois anos" (MARCEL, 1964, p. 54). Henri Bergson é o mestre a quem Marcel dedicou uma de suas principais obras: "Le Journal Métaphysique, publicada em 1927. Sobre as perspectivas de aproximação e ampliação dos pensamentos de Bergson e Marcel, Cf. "L'immédiat chez Henri Bergson et Gabriel Marcel" (TSUKADA, 1995). 
Após obter a agregação em Filosofia, Marcel passa a lecionar e exercer a atividade pedagógica em vários centros de Ensino Secundário. Como professor, ensinou em Vendôme (1911-1912), no Liceu Condorcet (1915-1918), em Sens (1919-1922), durante a segunda guerra, em substituição a professores mobilizados e/ou prisioneiros, no Liceu Louis-le-Grand, preparando os alunos da Escola Normal (1939-1940) e no l'Institut Montpellier (1941). Mais ainda: foi professor visitante na Universidade de Aberdeen, na Escócia, em 1951 e 1952, e na Universidade de Harvard, nos Estados Unidos, em 1961 e 1962. Em 1952, foi eleito membro da Académie des Sciences Politiques et Sociales de l'Institut de France, além de atuar, de 1957 a 1961, como presidente da Association Montessori $^{8}$ de France, tendo permanecido como presidente honorário até o fim de sua vida9.

${ }^{8}$ A participação de Gabriel Marcel no processo de implantação da Pedagogia Montessori, na França, não pode ser vista apenas como a de um mero figurante. Numa carta, inédita, datada de 26 de junho de 1959, o filho de Maria Montessori escreve "Je vous suis bien reconnaissant de votre lettre et de votre intervention qui, encore une foi, démontre votre intérêt pour l'oeuvre de $\mathrm{Mm}$. Montessori. Comme vous savez, mon plus grand souci est de la faire connaître et de la répandre. Je suis donc toujours plus qu'heureux quand je trouve une institution ou une personne qui m'aid à faire (Carta inédita, Bibliothèque Nationale de France, Paris, 1959 (Carton 97).

9 Gabriel Marcel foi um pensador influente das Ciências Humanas. Entre as dintinções que recebeu como sinal de reconhecimeto por seu trabalho e produção destacam-se: Prêmio de Literatura da Acadêmia da França, 1949; Eleito Membro da Acadêmia de Ciências Moraes, 1952; Prêmio Goethe da cidade de Hamburgo, 1956; Prêmio Nacional de Letras, 1958; Comendador da Ordem das Artes e das Letras, 1958; Comendador da Ordem das Palmas Acadêmicas, 1958; Prêmio Asiris; Grande Prêmio
Ao analisar, em Gabriel Marcel, a relação que há entre o filósofo e o educador, fica suficientemente claro o quanto a educação, enquanto processo de formação humana, precisa se constituir numa expressão da confiança no Ser, no humano, que, resistindo às seduções dos modismos e das manipulações das técnicas de aviltamento, visa fornecer ao homem/educando as condições necessárias para alcançar o fim autêntico de sua vida: a coerência de si (MARCEL 1971).

"Penso que ao educador-filósofo digno de sua missão incumbiria combater diretamente as forças subreptícias que tendem à neutralização do passado e pela sua ação conjugada suscitam o que chamarei insularização temporal do homem contemporâneo" (MARCEL, 1951b, p. 37). Isto significa que, em sentido profundo, é preciso que o educador, atento às questões do seu tempo, não perca a visão do que é o humano, nem o contato com os âmbitos da sua realidade, que assim ficam reduzidos à simples menção abstrata. Neste caso, consideramos que a educação procura contribuir para que o homem, no contexto da técnica e da tecnologia, restaure a unidade entre a condição humana e a problematização poéticofilosófica, tanto da construção da sua visão de mundo, como de sua ressignificação existencial.

Assim, queremos refletir sobre o modo como o Pensamento de Marcel, como esforço filosófico de pensar o homem e sua formação, procura por um lado, interrogar sobre os desafios da formação humana na

Internacional da Paz pelos Livreiros e Editores Alemães, 1964; Prêmio Erasmo, 1969; entre outros. 
era da técnica e tecnologias da informação e, por outro lado, equacionar as vias de aplicação da formação humana, para a construção de uma abordagem antropológica e existencial da educação.

\section{Exigências educativas da formação humana numa era de técnica e tec- nologias da informação}

Gabriel Marcel (1933, 1940, 1956), ao discutir sobre a influência do saber objetivo sobre a condição humana, não só critica os pressupostos dos saberes prontos e acabados como ressalta o verdadeiro sentido da educação, cujo objetivo visa fornecer ao homem as condições necessárias para alcançar o fim autêntico de sua vida.

Sob o ponto de vista das exigências educativas da formação humana, na era da técnica e da tecnologia, destacamos a necessidade da educação, de procurar, primeiro, resgatar e responder à formação integral do ser humano; segundo, responder às necessidades da era da técnica e da tecnologia e, por último, possibilitar, através da vivência da prática pedagógica, a redescoberta da noção de sabedoria.

\subsection{Resgatar e responder à formação in- tegral do ser humano}

Durante as três primeiras décadas do século vinte, na Europa, uma imagem do homem bem definida orientou pais e mestres na tarefa de educar as novas gerações. A concepção antropológica acerca do humano, que apontava para um desenvolvimento paulatino, seguro e linear de sua formação, foi fruto de uma fé nas boas energias cria- doras de um homem que se desenvolvia contínua e ininterruptamente para melhor.

Com base nestas "certezas", houve um investimento na formação da criança e na preservação da juventude, através de uma educação que visava despertar suas qualidades vitais e garantir a prevenção e solução dos problemas individuais e sociais da presente era. A tendência pela busca originária da essência do homem, atrelada à crença de que estava surgindo uma nova e melhor sociedade (BOLLNOW, 1971).

No centro da compreensão pedagógica, estava á concepção Essencialista de homem, onde o professor partia de uma definição pré-concebida sobre o que constituía o humano e o que se queria fazer dele e/ou formar nele uma ideia universal sobre o que era o homem e o modo como devia ser sua educação. Na base deste arrefecimento antropológico e pedagógico encontraram-se, conforme Bollnow, pelo menos dois fatores:

De um lado, o mundo da técnica moderna, mais realista, mais duro, com seu clima e a experiência do trabalho revelou os limites de um desenvolvimento pleno e global das forças do homem [...] Do outro lado, a verificação e o conhecimento dos condicionamentos hereditários arrefeceram o entusiasmo pela educação, reduzindo 
seu ideal a proporções mais modestas (BOLLNOW, 1971, p. 17).

É a partir desta dura realidade que Gabriel Marcel (1940, 1951b, 1956, 2003) chama a atenção para a necessidade de pensar sobre: o que é o homem? Quem sou eu? Será que a visão que temos do humano é suficiente para assimilar suas experiências pessoais e existenciais? A formação do homem deve reduzir-se apenas à dimensão técnico-racional?

De acordo com Marcel, a civilização industrial perdeu a consciência do que é o humano. "Só conhece algumas dimensões do indivíduo; o homem integral, individualmente considerado, não existe para ela" (1951b, p. 207). Na sociedade da técnica o homem está limitado à dimensão técnicoracional. Submisso às imposições dos processos de funcionalização, o homem passa a viver como uma máquina, de modo condicionante e alienado de si, numa situação onde seu valor é posto em dúvida, à medida que a ideia de pessoa é utilizada, muitas vezes, superficialmente e, em proveito de causas, por homens movidos pela tendência à exploração, pelo desejo de opressão e a favor de grupos e interesses econômicos e sócio-ideológicos.

Ao falar sobre a integralidade do Ser, Gabriel Marcel (1951a, 1951b) não a compreende como sinônimo das concepções de plenitude e integralidade. A categoria da integralidade compreende uma visão ampla e abrangente do homem. Seu significado não comporta os sentidos de esgotabilidade, completude, acabamento e perfeição das disposições e partes constituintes do ser humano.

De acordo com a visão antropológica marceliana, a noção de integralidade do Ser envolve: a dimensão físico-corporal, por conceber o homem enquanto ser encarnado; a dimensão sensorial, quando possibilita o desvelar da existência, através da mediação do corpo e das relações sentidas; a dimensão cognitiva, por onde se testemunha que o mistério do Ser pode ser apreendido, mas nunca esgotado totalmente; a dimensão emocional, por compreender que a existência se afirma na relação intersubjetiva do eu e do tu; e, por último, a dimensão espiritual, que inclui o processo de busca pela unificação da alma através do agir coerente, da possibilidade da transcendência e do encontro com o Absoluto.

A indissociabilidade entre a dignidade humana e a ética confirma-se no pensamento de Marcel, nas obras "Journal Métaphysique" (1927), "Homo Viator" (2005), "Ser y Tener" (2003), "Los Hombres Contra Lo Humano" (1951b) e o "L'homme Problématique" (1955). Este é um conjunto de produções no qual ele se opõe a tudo aquilo que ameaça o humano e sua existência concreta, quando sua intenção é mostrar que há algo de precioso no humano que precisa ser preservado: "a honra de ser homem" (MARCEL, 1951b, p. 225).

\subsection{Responder às necessidades da era da técnica e das tecnologias da informa- ção}


Os desenvolvimentos da técnica e da tecnologia introduziram, através dos seus avanços, uma acelerada e vertiginosa acumulação de materiais, instrumentos e conhecimentos. O processo de aperfeiçoamento da técnica e a criação de novos mecanismos tecnológicos subverteram a ordem de valor e das relações entre o humano e a máquina, a informação e a comunicação, o Ser e o ter (MARCEL, 2003). Os progressos técnicos e tecnológicos, portanto, se constituem como a base de construção de uma mentalidade específica, onde a concepção de homem se confunde com as noções de organização, burocratização, função e produtividade.

"A vitória do industrialismo é a mais profunda ruptura com o passado, autêntica 'nova barbárie', onde o interesse dos homens se transladou dos valores da vida para os valores pecuniários" (VITA apud ORTEGA Y GASSET, 1963). A tecnização substituiu a subjetividade pela uniformidade; o elemento orgânico, pelo aparato mecânicoorganizado e instaurou o culto dos valores instrumentais e utilitaristas. Neste sentido, "vemos que os progressos da técnica, in concreto', acentuam a redução progressiva da diversidade humana, um nivelamento extraordinário das sociedades, do modo de viver" (MARCEL, 1951b, p. 198).

Esta redução progressiva da diversidade humana se deu em virtude das descobertas tecnocientíficas. Ancorado no paradigma cibernético, o homem depositou, nos meios de comunicação de massa e nas máquinas, a crença no desenvolvimento das sociedades e no aperfeiçoamento das civilizações. A subjugação da técnica e da ciência aos interesses do Estado acabou por difun- dir a crescente necessidade de unificação e uniformização dos comportamentos e modos de existências (JASPERS, 1933; MARCEL, 1951b).

Na despersonalização do Ser e na sublimação do fulcro espiritual da vida, o homem se reduz, progressivamente, ao nível da coisa e da função. Na ênfase em torno do fortalecimento dos processos que pretendiam a regularidade da vivência humana, a cultura da técnica excluiu a novidade, a espontaneidade e as possibilidades ressignificantes da própria existência do Ser. Munido pelo princípio da ação mecânica, o homem buscou a uniformização dos modos de pensar, crer, sentir, desejar e viver das pessoas. $\mathrm{Na}$ base, estabeleceu-se a antinomia homem-técnica, enfatizou-se o automatismo e advogou-se a favor do predomínio dos meios científico-tecnológicos, como instrumentos de disciplina, educação e sentido último da vida.

Na concepção de Gabriel Marcel, "vivemos num mundo que parece construído sobre a recusa de refletir" (1951b, p. 117), num mundo governado pela máquina, onde o repertório das ações mecânicas pretende, na adaptação do sujeito ao meio, subordinar a existência humana a uma atmosfera antiespiritual de degradação do Ser, por meio da manipulação das consciências e da educação das massas.

Na obra Aproximacion Misterio del Ser: posición y aproximaciones concretas al misterio ontológico, Gabriel Marcel afirma que "a época contemporânea se caracteriza por algo que poderia chamar-se, sem dúvida, a desorbitação da ideia de função" (MARCEL, 1987, p. 23), quando o indivíduo tem sido tratado, diante de si mesmo e da 
sociedade, como uma simples peça da grande engrenagem, que é o mundo. Neste sentido, o teórico nos alerta sobre o perigo do humano sucumbir ao império da técnica e aos mecanismos determinantes da indústria e dos processos de produção em série. Voltado para a concepção de homem, difundida no período da Revolução Industrial, Marcel nos descreve o modo como a condição existencial do Ser foi levada à noção de função.

As técnicas, diz Marcel, possuem “[...] um valor positivo à medida que se colocam para além da utilidade pura e simples" (1955, p. 27). Na base, elas "não são más em si mesmas" (MARCEL, 1951b, p. 238), porque representam a expressão da capacidade criativa, inventiva e transformadora do ser humano. Implica que o desenvolvimento humano não pode limitar-se à superficialidade do mundo artificial dos processos de fabricação e produção de mão de obra. As particularidades do fazer da máquina não podem se dissimular nas especificidades da formação integral e espiritual do ser humano.

Na perspectiva de Marcel (1951b), o objetivo da educação não é primeiro formar cientistas, inventores, produtores e/ou consumidores. Antes, seu papel é promover a humanização e a transcendência do Ser; é contribuir para que o homem se desenvolva em todas as suas dimensões. Assim como o homem não se define no ato da sua concepção, também não pode achar-se concluído ao término dos processos de escolarização e especialização técnica.

Implica em não aceitar a concepção de progresso como a expressão “[...] de um realismo que exclui a noção concreta do espírito" (MARCEL, 1927, p. 122). Implica, ainda, em compreender que todo progresso expõe não só os limites da realidade na qual se inscreve, como anuncia o princípio de uma nova possibilidade que lhe abrange, excedem e transcendem.

\subsection{Possibilitar a redescoberta da noção de sabedoria}

As eras da técnica e da tecnologia se assentam nos pressupostos da descoberta e da cultura do novo. Submisso ao ciclo empírico da produção, distribuição e consumo, o homem perdeu a noção de si e passou a existir conforme o caráter abstrato do meio industrial. Conduzido por uma concepção objetiva de mundo, cedeu aos ditames da tendência “[...] que procura identificar o valor de um ser com o rendimento que ele pode dar" (MARCEL, 1951b, p. 156-157). O homem abriu mão dos testemunhos insignes da história e relegou ao status de inferioridade pessoas, lugares, monumentos, modos e expressões da presença do Ser no mundo. Em nome do desenvolvimento técnico, o homem também abriu mão de sua herança espiritual (MARCEL, 1955).

As transformações destas perspectivas estão presentes e ligadas a um sentimento de impaciência crescente. Pelo fato do homem tomar a noção de rendimento, como único critério aceitável do valor humano, a realidade tem sido submetida aos domínios da economia e do mercado. Com base neste critério, violenta-se a natureza para realizar um determinado plano abstrato. O mundo é transformado num habitat roto (MARCEL, 1956); os monumentos históricos são deplorados e usados como depó- 
sitos e/ou espaços comerciais; as relações humanas tornam-se pragmáticas; a cultura, a filosofia e as produções artísticas são desorbitadas e a educação se confunde, cada vez mais, com meros processos de escolarização e transmissão de informações e conhecimentos.

Neste sentido, percebemos que a noção de herança espiritual se perde. Já não é mais reconhecida como tal. A herança espiritual não se situa no âmbito das coisas; ela circunda a dimensão espiritual. Ela diz respeito ao "[...] papel do espírito quando consiste em voltar a partir de cada momento a remontar em particular signos de uma realidade significativa, que deve sempre ser redescoberta, porque é em si refratária a toda possível transmissão" (MARCEL, 1956, p. 52).

Por um lado, vemos a técnica e a tecnologia se constituírem no espectro de dominação do mundo, e num conjunto de processos puramente assimiláveis. Por outro lado, reconhecemos a necessidade de buscar construir uma mentalidade multidimensional, que consiga dialogar com o homem e a realidade, a partir de uma concepção de conhecimento capaz não somente de levá-lo a uma visão ampla do mundo, como de restituir-lhe seu valor e sentido existencial. Esta mudança do homem preconiza a formação humana, como condição indispensável para o desvelar e o transcender de si, algo que poderá se realizar pelo despertar da noção de sabedoria.

A sabedoria, da qual nos fala Gabriel Marcel, não consiste num acúmulo de conhecimentos técnicos ou aparatos científicos. A sabedoria corresponde ao agir coerente, à busca pela unificação da alma, atra- vés da relação harmônica entre aquilo que sou, penso, sei e faço. Implica em procurar demonstrar de que maneira a condição encarnada do Ser poderá contribuir para levar o indivíduo a encontrar, através da compreensão multidimensional do homem e da realidade, seu caráter ontológico e peso existencial.

Ao contrário da técnica e da tecnologia, a sabedoria não pretende apenas a mudança do imediato ou a satisfação dos desejos e das necessidades. Pela sabedoria busca-se a integração à ordem universal. Sua perspectiva não dialoga com as tendências sistêmicas do idealismo, geocentrismo e/ou do antropocentrismo, porque na relação do homem com a realidade, a sabedoria "[...] se expressa e se orienta deliberadamente contra todos os “ismos"' (MARCEL, 1951a, p. 11). Na interface entre razão e sabedoria, a razoabilidade se apresenta como o princípio equilibrador entre os modos de apreensão, construção e transmissão de conhecimentos.

Na sabedoria não se afirma a completude do homem, "[...] se interroga pela totalidade do Ser e por mim mesmo enquanto totalidade" (MARCEL, 1987, p. 34). Por ela, o processo de desvelamento do homem sai da ordem da afirmação e ganha o estatuto ontológico da problematização, da inesgotabilidade e da indeterminação. Na sabedoria, o Ser adquire a primazia e o conhecimento se "[...] transforma num modo de participação do qual nenhuma epistemologia pode esperar dar conta porque ela mesma o supõe" (MARCEL, 1987, p. 37).

Educação para a sabedoria é aquela onde se propiciam as condições para que o discente aprenda, através da experiência 
sensível e da construção simbólica, a se relacionar com o mundo e com os diversos âmbitos da realidade local, global e multidimensional; a identificar e discernir atitudes, posturas, ideias, valores e aspirações, que ameaçam e comprometem a liberdade humana e os modos de organização do seu próprio existir.

Ao enfrentar o desafio que pretende a superação da complexa malha dos saberes totalitários, a educação para a sabedoria precisa se colocar, na era da técnica e da tecnologia, de forma crítica e a favor da dignidade humana; precisa posicionar-se a partir da consciência inalienável da própria concretude do homem.

Nenhuma educação que despreza as produções das atividades do espírito é digna deste nome. A sabedoria, que nasce dos saberes artísticos, poéticos, artesanais e filosóficos tende, inevitavelmente, a colocar-se contra o fanatismo e a demência das ideologias políticas, religiosas, econômicas e sindicais (MARCEL, 1955).

\section{Atribuições pedagógicas do educador- filósofo $^{10}$ na era da técnica e das tec- nologias da informação}

\footnotetext{
10 A relação entre o educador e o educando ao lado da discussão sobre a prática pedagógica, numa perspectiva da formação humana, é a temática central em torno da qual gira este último capítulo da tese. Queremos esclarecer aos leitores e leitoras que a questão que nos interessa é refletir a respeito do modo como, quem educa, se forma humanamente e, sobre como, quem aprende, pode se humanizar existencial e pedagogicamente. Queremos, ainda, chamar a atenção para a diferença entre o educador e o professor. Enquanto o professor subestima, no exercício da sua prática pedagógica, a necessidade de contribuir para estimular a consciência crítica do aluno, a respeito de si mesmo e do mundo, o educador procura apreender as condi-
}

\section{O pensamento de Gabriel Marcel} inscreve-se num contexto onde os discursos e debates sobre o predomínio da técnica, a emergência e a influência do cinema, do rádio, da televisão e da propaganda, como meios de comunicação de massa, estão a serviço da incidência da alienação e contra a dignidade do ser humano. Ao debruçar-se sobre o influxo destas técnicas de aviltamento sobre o comportamento do homem, o teórico empreende uma aguda crítica à realidade educativa do seu tempo, afirmando que "a educação não é amparo onde há desmoronamentos lamentáveis" (MARCEL, 1951b, p. 40).

ções em que a criticidade é possível, a partir da realidade e condição de Ser do próprio educando. $\mathrm{O}$ educador procura incentivar o educando a buscar os saberes que não são simplesmente transferidos, mas que precisam e podem ser desvelados e acessados de modo humano, espiritual e intersubjetivamente. Enquanto o professor dissocia, do ato de aprender, a necessidade da pesquisa, o educador compreende que o processo de formação humana também se desvela através da curiosidade epistêmico-ontológica e da atitude indagadora do Ser, que traz em si mesmo a consciência de que a prática educativa precisa se tornar, no quotidiano da vivência escolar, um testemunho rigoroso da busca pela realização de um trabalho coerente. Este é um trabalho pedagógico que não apenas se mostra academicamente significativo, mas que se anuncia enquanto processo gerador de sentido humano e existencial. É a atitude de alguém que, tomado pelo senso da própria condição humana, não nega suas contradições existenciais, nem sublima o caráter das suas próprias limitações teóricas e profissionais. Na busca pela formação de si mesmo e através da relação com o educando, o educador procura se colocar, de modo nada insinuante, não pretende ser modelo, transmitir receita e/ou repassar orientação, mas, comunicar simplicidade sublime, experiência e sabedoria. $\mathrm{O}$ educador procura se ressignificar humana, social, pedagógica, política e existencialmente. 
Esta foi uma época em que, segundo Marcel, a educação "(...) havia se transformado num sistema rígido e angustiante" (1940, p. 126), pois, “(...) o ensino era penoso ao espírito da criança, o sistema inteiro estava caindo aos pedaços, e era absolutamente certo, que para a maior parte das disciplinas o resultado fosse vazio e nulo" (MARCEL, 1951a, p. 45). Ao invés da educação desempenhar o papel de experiência formadora do desenvolvimento da consciência crítica dos alunos e núcleo fortalecedor de seu fulcro espiritual, transformou-se num tempo/espaço de conflitos e abstrações, que "[...] acabou contribuindo diretamente para debilitar a formação do ser ao seu estado anêmico" (MARCEL, 2005, p. 90).

Diante destas dificuldades e sob a ameaça que o espírito de abstração tem exercido sobre as consciências humanas, num período de desenvolvimento tecnocientífico, Gabriel Marcel procura fazer, na obra Os Homens Contra o Homem (1951b), uma reflexão-crítica sobre o papel do educador-filósofo face à "essência da realidade espiritual [...] de um mundo destroçado e em guerra consigo mesmo" (MARCEL, 1951a, p. 14, 32). Levando em conta estes pressupostos, destacamos as exigências que pesam sobre o docente, numa era da técnica e da tecnologia, procurando partir das condições gerais de suas possibilidades.

Num sentido amplo, a ideia do professor sofreu, no âmbito da cultura da indústria e da técnica, uma verdadeira degradação, na medida em que a noção de sabedoria perdeu seu ethos e o conteúdo substancial daquilo que o identificava como um ser de espírito livre e conhecedor da reali- dade (SARRAMONA, 1975).

Diante das mudanças e de outras exigências e a partir dos aspectos complexos da educação, Gabriel Marcel compreende que, em primeiro lugar, o educador deve procurar 'manter-se em guarda contra sua pretensa capacidade', precisa “[...] reconhecer seus limites e necessidades e ver que há domínios onde a sua incompetência é absoluta” (MARCEL, 1951b, p. 97). A prática docente não acontece no âmbito de uma realidade resistente, bruta, imóvel e impossível de mutação. A era da técnica e da tecnologia é mutante, complexa e fluída.

Em Aproximacion Al Misterio Del Ser: posición y aproximaciones concretas al misterio ontológico (1987), Marcel anteviu os efeitos que a revolução industrial e o triunfalismo tecnológico trariam sobre a imagem que o homem constrói de si e de suas respectivas consequências, do modo como os cidadãos modernos haveriam de lidar com os novos aspectos deflagradores de sua realidade. Neste sentido, o teórico adverte que o educador não pode permitir que sua atuação incorra em frivolidades, falsas lisonjas e/ou discursos pretensamente ideológicos e puramente publicitários (MARCEL, 1951b).

Se, por um lado, o educador-filósofo pode achar, diante dos desafios que lhe cercam, que deve ficar no campo das afirmações abstratas e/ou dos saberes que se pretendem absolutos, por outra parte, ele precisa reconhecer que o engajamento da prática docente se expressa pelo modo como cada um se compromete com as questões concretas do Ser, através da relação entre os fazeres e os dizeres, que são realizados dentro e fora dos espaços possibilitadores das vivências educativas e das aprendizagens. 
$\mathrm{O}$ ato de ensinar exige que o docente faça o discernimento entre a arrogância acadêmica e o espontaneismo da prática, entre achar que sabe de tudo ou que não deve comprometer-se com nada; este ato implica em procurar reconhecer que há domínios e saberes que a sua especialidade não alcança. Implica, ainda, em buscar o conhecimento de outras competências e categorias humanas que consigam proporcionar, ao exercício do ofício docente, as condições necessárias para o desempenho desejável dos seus próprios saberes e realizações pedagógicas (MARCEL, 1955; BOLLNOW, 1962, 1971).

Neste sentido, ao educador-filósofo cabe, num segundo momento, 'manter-se atento às questões humanas e às transformações do mundo', buscar questionar as ideologias e repelir os processos que reforçam a cultura do envilecimento e da submissão à servidão. $\mathrm{O}$ docente não pode colocar-se como "[...] um especialista de certo modo intoxicado pela própria especialidade" (MARCEL, 1951b, p. 92). A atuação docente nunca se dá no campo da neutralidade; jamais poderá fechar-se em si mesma, porque a produção dos saberes articula-se através das relações existentes entre a escola, a sociedade, o homem e a realidade.

Na determinação do pensamento, as palavras dos homens, em alguns momentos, constroem guetos, encerram-se em fórmulas precisas, comprometem a percepção da vida e tornam míope sua visão da existência. "Isolado o professor corre o risco de separar-se da vida e substituí-la insensivelmente pelo domínio de pensamento, espécie de jardim cerrado e bem tratado, onde ele muda cuidadosamente os arbustos"
(MARCEL, 1951b, p. 93). Na servidão, as palavras docentes e discentes constroem submundos, fecham-se, caem em condicionamentos e tornam estes sujeitos, escravos de ideias e concepções que ameaçam a liberdade de si mesmos e a vitalidade da relação com os outros e o mundo. Onde quer que a educação seja assim entendida, as possibilidades de transformação humana e intervenção social são reduzidas.

$\mathrm{Na}$ relação entre conhecimento e mundo é que surge, num terceiro aspecto, a necessidade do educador-filósofo 'procurar cultivar um olhar fenomenológico da situação fundamental do sujeito-educando' e empenhar-se em construir uma prática pedagógica do concreto. Para Marcel, as ideias e as concepções epistemológicas só fazem sentido quando são vistas a partir da própria realidade e do contexto imediato dos homens.

Realidade, existência e pensamento não devem/podem ser concebidos separadamente. Na fratura desta relação estão presentes: a força dos processos de abstração, a energia dos pensamentos sectários, o imperialismo da ditadura da ignorância e a legitimação dos discursos, propostas e posturas absolutistas, intolerantes e excludentes de concepções, culturas, experiências e pessoas.

Gabriel Marcel descreve seu método de investigação como uma forma de abordagem fenomenológica, que se dirige ao homem concreto. Sua intenção não se volta “[...] a uma inteligência abstrata e anônima, senão, a seres individuais em que pretende despertar uma certa via profunda de reflexão por uma verdadeira anamnesis no sentido socrático da palavra” (MARCEL, 1951a, 
p. 11). Esta forma de organização do pensamento expressa-se, deliberadamente, contra todos os 'ismos' ou sistemas fechados de interpretação do real, quando pretendem desvincular o Ser das situações concretas do seu próprio existir. "Não pode haver hoje uma educação-filosofia sem uma análise de essência fenomenológica sobre a atuação fundamental do homem" (MARCEL, 1951b, p. 108).

Na educação, o homem só se desenvolve humanamente quando ousa colocar, sob suspeita, as concepções e conclusões já assumidas; quando toma a iniciativa de problematizar suas verdades e a visão que tem de si mesmo e do mundo. Atrelado ao discurso existencial, a posição fenomenológica já anuncia que "a própria existência tem sentido e que toda significação é inseparável da existência" (REZENDE, 1990, p. 17). Ao falar sobre a fenomenologia do saber, no Diário Metafísico (1968a), Gabriel Marcel procura relacioná-la à compreensão que o homem tem de si. $\mathrm{O}$ processo de assimilação dos saberes implica no reconhecimento da condição encarnada e histórica do próprio ser humano. A mediação da corporalidade é que possibilita a construção do saber; algo que permite "[...] de início que a oposição entre sujeito e objeto seja transcendida" (MARCEL, 2003, p. 13). Deste modo, "O saber compreende em si a possibilidade de alternância do ritmo" (MARCEL, 1968a, p. 184) de cada pessoa, ao se apropriar dos conhecimentos que são necessários à vida. Ao professor, no processo de produção dos saberes, cabe respeitar as especificidades ontológicas do sujeitoeducando e o modo como a realidade é apreendida através da experiência subjetiva de cada um.

A partir das contribuições da atitude fenomenológica, professores e alunos poderão passar a considerar seus saberes como parte de uma realidade ampla, que, através do diálogo, tende a aprofundar-se e a alargar-se teórica e praticamente. Na busca pelo desdobramento dos significados, a obscuridade que separa os sujeitos é superada à medida que torna possível ver o outro como uma "[...] presença que está vinculada à alteridade" (MARCEL, 2003, p. 14); e também vinculada ao acolhimento, não só do que este outro diz, produz ou apresenta, como do que ele é e representa, enquanto Ser, subjetivamente encarnado.

Neste sentido, a educação pode tomar o mundo como referência, o educando, como centro e "as condições fenomenológicas como ato que implica sempre um comprometer-se" (MARCEL, 1951a, p. 347). Na intenção de corresponder às exigências deste comprometimento ${ }^{11}$, cabe ao professor-

\footnotetext{
"Antonio Muniz de Rezende, na obra Concepção Fenomenológica da Educação (1990) considera a maneira de trabalhar fenomenologicamente um processo educativo de formação humana. Ao acentuar o sentido e a força que o discurso pedagógico pode e/ou exerce sobre a prática docente e o processo de formação dos educandos, este teórico nos diz que, ao fazer fenomenológico, é preciso associar seu sentido pedagógico, estabelecer relações significativas entre os diversos elementos do fenômeno educacional e humano. A referência à Rezende e sua obra, no contexto deste trabalho de pesquisa, se dá por duas razões: primeiro, pela aproximação que há entre o papel da sua abordagem fenomenológica sobre a análise do discurso pedagógico e a compreensão fenomenológica do saber, descrita por Gabriel Marcel no Diário Metafísico (1968a); segundo, pelo fato de enxergarmos, no pensamento de Rezende, uma concepção fenomenológica da educação que se volta para educan-
} 
do numa perspectiva dos processos de desvelamento, que pretendem não só ajudá-lo a discernir os âmbitos da sua realidade, como contribuir com seu desenvolvimento humano e a ressignificação de sua própria existência. Neste sentido, ao fazer análises dos possíveis riscos e ameaças que perpassam a natureza do discurso pedagógico, Rezende compreende que é necessário o professor atentar para "[...] a discursividade do discurso pedagógico [...] e o alcance existencial da descrição. Isto significa, por um lado, o reconhecimento de que o sentido a ser aprendido é o da própria existência; e, de outro, que a questão comporta sentido [...] A compreensão, verificar o alcance simbólico do discurso, isto é sua capacidade de concentrar sentido, ao mesmo tempo, que sua capacidade tornar acessível o seu simbolismo [...] a interpretação que proporciona a densidade semântica nela contida [...] indagar de que maneira e até que ponto o discurso pedagógico contribui para a aprendizagem [...] igualmente, ênfase na corporeidade, insistência na significação dos procedimentos racionais abstratos, atenção especial à criatividade, à formação da vontade, ao exercício da liberdade [...] No que diz respeito à cultura a ser aprendida, os textos poderão fazernos ver, mais ou menos, a estrutura do mundo e sua complexidade [...] Mais ainda, o próprio texto pode ser analisado como fator de cultura. A produção de um texto é, também ele, trabalho gerador de cultura [...] Isto impõe a inserção do texto em seu contexto cultural e social de produção e comunicação [...] Significa que a visão do mundo manifestada pelo discurso pedagógico nunca é neutra [...] O reconhecimento da complexidade da nossa cultura não nos permite cair em qualquer forma de reducionismo: seja reducionismo tópico, enfatizando um tópico (a economia, por exemplo) em detrimento dos outros; seja o reducionismo radical, a-tópico, negando a própria realidades de uma cultura brasileira [...] Neste em muitos outros sentidos, o discurso pedagógico pode dificultar a apropriação da cultura, favorecendo ante os diversos processos de massificação e alienação cultural [...] E a questão se coloca de saber se, e em que medida, o discurso pedagógico se desenvolve como autêntica ação cultural [...] Todo discurso pedagógico encontra o problema da conscientização e se posiciona em relação a ele, ao menos implicitamente [...] Em relação à situação concreta de mundo, o discurso pedagógico poderá traduzir simplesmente um determinada hierarquia de valores, sem questioná-la, como poderá também pô-la em questão abrindo perspectivas para outros valores, numa nova forma de existência [...] Isto significa que todo texto, es- filósofo, num quarto momento, 'procurar desenvolver uma visão metafísica de suas concepções fundamentais'.

De acordo com Gabriel Marcel, "a crise do homem ocidental é uma crise metafísica" (1951b, p. 35), um acrisolar do humano, onde, na perda do contato real consigo mesmo, com o mundo e com os acontecimentos à sua volta, o homem se sente reduzido à simples menção abstrata.

Em nome do progresso e da produtividade, a que todo homem devia entregarse, instaurou-se uma política da totalidade, a crença numa existência da uniformização e se propôs uma educação voltada para a aquisição de domínios científicos e especializações técnicas. Ademais, admite-se que as questões referentes à educação estão suficientemente construídas; assim, caberia uma preocupação com questões de ordem prática e de cunho metodológico: promover

crito ou falado, é confrontado com o problema da revolução cultural [...] Igualmente, as posições declaradamente implicadas na problemática da ação cultural e da revolução podem afinal conter limitações que reduzem de modo sensível o seu alcance [...] Qual é então o projeto cultural contido no discurso pedagógico? Há sempre um projeto, ao menos implícito, nas análises, nas críticas, no exame dos problemas. Quais os objetivos educacionais explícitos ou implícitos nos textos e em suas críticas? Reconhecendo que a ideologia não é apenas uma falsa consciência, mas a manifestaçãoocultamento do desejo, indagamos que desejo é este subjacente ao texto e de que maneira este mesmo texto contribui para a manifestação ou abafamento das aspirações humanas? Finalmente, como um texto, na instituição escolar, nunca é utilizado de maneira isolada, nos perguntamos qual o discurso pedagógico que emerge do conjunto dos textos preferidos, em função de um currículo e de sua integração, tanto horizontal como vertical" (REZENDE, 1990, p. 88-9o). 
a implementação de propostas curriculares, cujos fundamentos apontam para uma concepção da realidade que se anuncia, pretensamente, como concretizada. Entretanto, ao falar sobre a necessidade do educadorfilósofo procurar desenvolver uma visão metafísica de suas concepções fundamentais, Marcel propõe questionar a natureza do cerceamento do processo educativo, buscando problematizar as concepções de senso-comum, a partir de uma visão integral do ser humano e do reconhecimento de que "[...] há no ser humano tal como nós o conhecemos algo que se rebela contra esta espécie de violação ou desvinculação de que é vítima” (MARCEL, 1951a, p. 41).

Ao pretender construir uma concepção educativa do humano, a partir da visão metafísica de suas concepções fundamentais, Marcel anuncia uma total recusa a toda pretensão idealista do homem e da própria educação; e a procurar "[...] mostrar como o Idealismo tende inevitavelmente a eliminar toda consideração existencial" (MARCEL, 1968a, p. 14). À educação, na intenção de superar toda concepção totalitária do ser humano, cabe, continuadamente, a renovação de seus pressupostos teóricos e a libertação de todas as categorias que limitam a compreensão humana à ordem da quantidade e do quantificável. "Cumpre à imaginação metafísica proceder a uma renovação das categorias fundamentais" (MARCEL, 1951b, p. 109) do Ser e sua formação.

Consciente de sua própria condição metafísica e movido por uma visão ampla acerca do humano, o educador tentará compreender que a educação não pode limitar-se a um simples processo de produção e rendimento, e que o educando não deverá ser pensado ou condicionado ao nível da máquina ou da função. $\mathrm{O}$ educador precisa conscientizar-se de que o indivíduoeducando não é redutível a uma ficha, nota, conceito, caderneta ou número, através de elementos determinantes de seu futuro ou da sorte que lhe caberá. Em tais condições, o Ser autenticamente criador é suplantado, ignorado, humilhado e aviltado na sua condição humana e na sua relação intersubjetiva.

Os postulados da visão metafísica do humano e de sua relação intersubjetiva equivalem a dizer "[...] que o homem deve ser apreendido como uma participação efetiva” (MARCEL, 2003, p. 133), que caberá ao educador-filósofo, num quinto momento, no comprometimento de si, 'buscar a coerência entre um agir ético e uma visão ampla do humano', no âmbito de suas relações sociais e de seu fazer educativo. $O$ fazer pedagógico nunca se encerra nele mesmo. Nenhuma teoria, método, conteúdo ou prática educativa terá sentido se não se relacionar ao homem e à sua própria existência. Pela educação, não somente educandos se formam, mas educadores também se fazem, se constituem, desenvolvem-se e podem avançar no processo de maturidade e formação humana.

Ética, visão e relação intersubjetiva são aspectos do fazer educativo que se interpenetram, nutrem-se, ajudam-se e complementam-se. Articulados, poderão nos levar à compreensão de que "as ideias só tem vida se o espírito lhas conserva, julgando-as sempre, quer dizer, mantendo-se mais alto, e que elas deixam de ser boas e até de ser ideias quando deixam de ser a base sólida e a expressão em ato da liberda- 
de interior" (MARCEL, 1951b, p. 100). Toda prática pedagógica que se pretende humana e humanizadora dos homens e dos processos educativos deve procurar buscar a coerência entre um agir ético e uma concepção ampla acerca do humano e dos processos possibilitadores do seu desenvolvimento.

A coerência entre os fazeres e os dizeres docentes só é possível a um Ser cuja existência esteja comprometida com sua própria formação. A articulação entre ser e fazer é mais importante ao educador, que seu discurso ou simples domínio cognitivo de teorias. Na ausência desta coerência, a prática docente "[...] tende invariavelmente a obliterar-se na consciência do filósofoprofessor para quem o seu sistema tende a substituir o mundo e a vida" (MARCEL, 1951b, p. 108).

"Assumir uma postura ética trata-se de uma opção decisiva, de uma escolha entre ser e não-ser" (MARCEL, 1951b, p. 113), entre enfeudar-se ou comprometer-se existencial e pedagogicamente. Implica em dizer que as intenções docentes e os fins da educação, por melhores que sejam, pouco servirão ao processo de formação humana dos alunos, se os próprios educadores não se tornarem uma expressão viva daquilo que ensinam e do seu comprometimento. Neste sentido, não se deve entender que ao educador caberá indicar ao educando qual é o caminho a ser seguido ou, quem sabe, o exemplo a ser copiado. O que se pretende não é que o docente seja visto como um modelo ou padrão, senão, que cada aluno, contemplando seu agir ético, sinta-se motivado a realizar, na busca pela construção de si, “[...] não um trabalho malfeito, mas um trabalho coerente" (BUBER, 2011, p. 27).

\section{Considerações finais}

O papel do educador-filósofo, na era da técnica e das tecnologias d informação, é colocar-se como sujeito mediador dos processos de ensino e aprendizagem; discernir entre o profetismo pedagógico e a pedagogia da esperança "[...] sem pretender exceder a experiência e fundar as suas próprias profecias sobre a ciência, a biologia, a economia ou a sociologia" (MARCEL, 1951b, p. 115). É seu papel, ainda, compreender que o fazer pedagógico passa, direta e transversalmente, pelos caminhos sinuosos das experiências contínuas e descontínuas da formação humana. Ao educador-filósofo cabe problematizar as concepções e aos saberes que orientam sua prática e denunciar, incansavelmente, a ilegitimidade das posturas aviltantes e ideológicas.

O educador-filósofo, no mundo atual, busca sempre compreender, que a audácia da confiança, que o educador deposita no educando, pode lograr êxito, através do testemunho pessoal de uma ação pedagógica que demonstra, conscientemente, o esforço de não se deixar desanimar nem sucumbir, não obstante as decepções e desconfianças que o assediam e o ameaçam existencialmente (MARCEL, 1927). Enfim, o educador-filósofo evita que os domínios da técnica e da tecnologia violem e/ou determinem o fulcro de sua condição existencial, procurando sempre questioná-los, à luz da esperança e da fé que necessitamos sempre conservar com relação ao humano e suas possibilidades. 


\section{Referências}

BOLLNOW, Otto Friedrich. Filosofia existencial. São Paulo: Saraiva, 1946.

Pedagogia e Filosofia da Existência: um ensaio sobre formas instáveis da educação.

Petrópolis, RJ: Vozes, 1971.

BUBER, Martin. O caminho do homem segundo o ensinamento chassídico. São Paulo: Realizações Editora, 2011.

CARMONA, Feliciano Blázquez. Marcel - 1889 - 1973. Madrid: Ediciones del Orto, 1995.

HUISMAN, Denis. História do existencialismo. Bauru; SP: EDUSC, 2001.

JASPERS, Karl. Ambiente espiritual de nuestro tiempo. Barcelona - Buenos Aires: Labor, 1933.

MARCEL, Gabriel. Jornal metafísico. Madrid: Gallimard, 1927.

. Le monde cassé. Paris: Plon, 1933.

. Essai de philosophie concrète. Madrid: Gallimard, 1940.

El misterio del ser. Buenos Aires: Editora Sudamericana, 1951a.

. Os Homens contra o homem. Porto: Editora Educação Nacional, 1951b.

L'homme problématique. Paris: Aubier, 1955a.

. Decadencia de la sabiduría. Buenos Aires: EMECÉ, 1955b.

. Diário metafísico: 1928-1933. Madrid: Ediciones Guadarrama, 1968a.

. Entretiens Paul Ricoeur et Gabriel Marcel. Paris: Aubier Montaigne, 1968b.

. O conceito de herança espiritual. In: RUITENBEEK, Hendrik M. O dilema da sociedade tecnológica. São Paulo: Vozes, 1971.

L'esthétique musicale de Gabriel Marcel. Cahier no 2-3, Présence de Gabriel Marcel, Paris, Aubier, 1980.

. Obras seletas I: el misterio del ser, el dardo, la sed, la señal de la cruz. Madrid: Biblioteca de Autores Cristianos, 2002.

Ser y tener. 2. ed. Madrid: Caparrós Editores, 2003.

$\overline{\text { Sígueme, } 2005 .}$

REZENDE, Antônio Muniz de. Concepção fenomenológica da educação. São Paulo: Cortez; Autores Associados, 1990.

SARRAMONA, Ferrandez. La educación: constantes y problemática actual. Barcelona: Ediones CEAC, 1975.

TROISFONTAINES, Roger. Gabriel Marcel. In: LELOTTE, J. S. F. (Org.). Convertidos do século XX. 2. ed. Rio de Janeiro: Agir Editorial, 1966.

TSUKADA, Sumiyo. L'Immédiat chez Henri Bergson et Gabriel Marcel. Paris: Louvain, 1995. 